\title{
Studies on Formulation and Evaluation of Eudragit RS PO Based Nanoparticulate System of Aceclofenac for Ocular Delivery
}

\author{
Sfurti Sakhare ${ }^{1, \star}$, Sachin Dnyandeo Shinde1, Adhikrao Venkatrao Yadav¹, Amol Somnath Shete ${ }^{2}$ \\ ${ }^{1}$ Department of Pharmaceutics Gourishankar Institute of Pharmaceutical Education and Research, Limb, Satara, Maharashtra, INDIA. \\ 2Department of Pharmaceutics, Krishna Institute of Pharmacy of Krishna Institute of Medical Sciences (Deemed University), Karad, \\ Maharashtra, INDIA.
}

\begin{abstract}
Aim: Ocular drug delivery is the most challenging and interesting goal in front of the pharmaceutical scientist. Ocular inflammation is the most commonly affecting disease of the eye. The objectives of present investigation were to formulate and evaluate eudragit RS PO (ERS PO) based Aceclofenac (ACF) Nano suspension for ophthalmic application. Materials and Methods: The ACF Nano suspensions were prepared by Nano precipitation method and the optimized formulation was lyophilized and further characterized for, particle size, polydispersity index, zeta potential, drug entrapment efficiency, in-vitro drug release study, pH study, ex-vivo trans corneal study, corneal hydration (\%) study, Fourier Transform Infrared spectroscopy (FTIR), Differential Scanning Colorimetry (DSC), X-ray Diffraction (XRD) and Scanning Electron Microscopy (SEM). Results: The optimized ACF Nano suspension was compared with standard ACF solution prepared according to USP. The Nano suspensions were prepared successfully by Nano precipitation method. The FTIR, DSC and XRD studies confirmed absence of drug-polymer interactions. DSC and $X R D$ results reflected the amorphization of drug in formulation. The SEM images revealed that there will be no irritation cause after ocular administration due to spherical and smooth surface. The results of in vitro drug release study indicated that higher \% entrapment efficiency of drug in Nano suspension delays the drug release and increase the corneal residence time. Conclusion: From ex vivo trans corneal study it was found that optimized formulation showed higher \% permeation of drug as compared with $0.1 \%$ Aceclofenac solution with no signs of corneal damage and eye friendly behavior.
\end{abstract}

Key words: Aceclofenac, Nanosuspension, Occular, Eudragit, Permeation.

\section{INTRODUCTION}

Ocular drug delivery is today's one of the most challenging and interesting goal in front of the pharmaceutical scientist. The delivery of drugs to the certain areas of the eye is relatively inaccessible by systemic route and it has been a difficult task because of the complex anatomy and physiological barriers of the eye. ${ }^{1}$ Ocular inflammation is the most commonly affecting disease of the eye. Inflammation is caused by a cellular and vascular response to the injury, ischemia, infection and excessive or inappropriate operation of immune mechanism. The response is raised by release of some chemical mediators such as acidic lipids e.g. prostaglandins, leukotriene's, vasoactive amines, thromboxane's, cytokines etc and activation of inflammatory cells., ${ }^{2,3}$ Medications administered via topical route offers advantages like rapid action, avoidance of hepatic first-pass metabolism, avoidance of systemic side effects, patient compliance etc. Moreover, certain areas of an eye are relatively inaccessible to drugs delivered by systemic route because of different physiological barriers of eye such as the epithelial, blood-retinal barrier and blood-aqueous barrier. ${ }^{1}$ The use of
Submission Date: 22-04-2020; Revision Date: 27-07-2020; Accepted Date: 23-10-2020

DOI: 10.5530/ijper.55.1s.40 Correspondence: Ms. Sakhare Sfurti Shamling Gourishankar Institute of Pharmaceutical Education and Research, Limb, Satara- 415002,

Maharashtra, INDIA. Phone no: +919657065059 Email id: sfurti_28@rediffmail.com

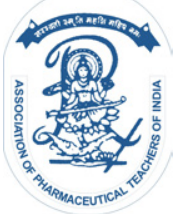

www.ijper.org 
topical therapy of corticosteroids is quite common in the treating ocular inflammatory disorders, allergic diseases and dry eye syndrome but the corticosteroid's use is often limited and associated with severe adverse effects such as increase in intraocular pressure, cataract formation, glaucoma progression and risk of infection. ${ }^{4}$ To devoid these severe side effects, non-steroidal antiinflammatory drugs (NSAIDs) have been found to be safer alternatives to steroids in treating inflammation at ocular site..$^{5}$ Aceclofenac, BCS class II, is a NSAID which is structurally similar to diclofenac. Aceclofenac acts by preferential selective inhibition of cyclooxygenase-2 (COX-2) after conversion into an active metabolite which could be excessively beneficient in ocular inflammation. ${ }^{6}$ Aceclofenac also have inhibitory effect on the tumor necrosis factor- $\alpha$ and interleukin-1 secretion. Furthermore, Aceclofenac have good antiinflammatory, analgesic activities and have better gastric tolerability as compared with some other NSAIDs i. e. diclofenac and indomethacin.

Mostly, all ocular medications has been given to the patient as aqueous solution but $90 \%$ of the topically applied dose from such aqueous solutions is lost because of the rapid tear turnover and pre-corneal losses i. e. lacrimation and drainage that lead to less ocular bioavailability. ${ }^{7}$ Hence, there is a grateful need for an ideal ocular drug delivery system which could increase the contact time of the drug molecule with the eye surface and promote the transport of drug molecules into the eye tissue.

Various approaches that have been used earlier for enhancement of ocular bioavailability include use of viscosity and penetration enhancers, ocular inserts, pro drug approach and in situ gel. These approaches are suitable to solve the problems of less permeable drugs but could not resolve the issue of less water soluble drugs. Furthermore, these formulations are noncompliant which lead to blurring of the vision due to increasing viscosity, using gels, inserts etc. ${ }^{8}$

Nanotechnology and particle-engineering is a rapidly developing field in which Nano precipitation have been used to improve stability of poorly soluble drugs. Along with improving stability, Nano precipitation method is used to enhance aqueous dissolution rate and ocular availability of less water soluble drugs. ${ }^{\text {? }}$

There are various colloidal drug delivery approaches such as polymeric micelles, liposomes, nanocapsules/ nanoparticles; dendrimers possess all the important characteristics for improved ocular bioavailability. Nanoparticles have well tolerability and deposits in the cul-de-sac of an eye for prolonged time period because of their small size. Nanoparticles also prolong the drug residence time and ensure the optimal contact between the eye mucosa and the formulation resulting in sufficient drug concentration in ocular tissues. ${ }^{10}$

Nano particulate drug delivery approach has been widely used to avoid the limitations of the conventional ocular formulations like eye drops, suspensions such as overcoming various disadvantages of aqueous drops like rapid tear turnover, lacrimation, drainage, blinking reflex etc. Other advantages of nanoparticles include, prevention of any sight impairments of eye and is well tolerated which helps to increase patient compliance. Moreover, self-administration as compared to the implants and other devices is possible. ${ }^{11}$

Due to the above mentioned reasons, an ophthalmic drug delivery system approach such as Nano suspension which is used to overcome the various disadvantages of conventional ocular dosage forms, possesses controlled or sustained delivery of ophthalmic drugs with increase in corneal residence time and enhances aqueous solubility of BCS class II drugs would be beneficial. ${ }^{12}$ Nano suspensions are defined as biphasic system and colloidal dispersions composed of drug particles which are dispersed and suspended in an aqueous solvent in which the diameter of the particles is less than $1000 \mathrm{~nm}$ in size. ${ }^{13}$ Eudragit RS PO is a copolymer of poly(ethylacrylate, methyl-methacrylate and chlorotrimethylammonio ethyl methacrylate) which contains 4.5-6.8 $\%$ of quaternary ammonium groups, hence due to its positively charged surface that interacts with negatively charged drugs or with the cellular surface of a target tissue such as anionic cornea. Therefore positive charge on polymer is responsible for its mucoadhesive property. ${ }^{14,15}$ It has been previously stated, in treating ocular inflammatory disorders, NSAIDs are superiorly preferred instead of steroid like drugs because of less ocular adverse effects. Among the NSAIDs, one could present therapeutic benefit by selectively inhibiting COX-2 enzyme, as COX-2 produces prostaglandin at the site of inflammation. Thus, Aceclofenac is a COX-2 inhibitor and seems to be an ideal candidate for treating ocular inflammatory conditions.

The objective of the present research was to formulate and evaluate eudragit RS PO (ERS PO) based Aceclofenac (ACF) Nano suspension for ophthalmic application and to improve ocular bioavailability of Aceclofenac.

\section{MATERIALS AND METHODS}

\section{Materials}

ACF was received as gift sample from Ranbaxy Research Lab-oratories (Gurgaon, India). Eudragit RS PO was 
procured from Roehm Pharma polymer, Degussa, Mumbai. All other chemicals utilized were of analytical grade agents and fresh eyeballs of goat were purchased from local butcher's shop (Satara, India) within one hour of animal slaughtering.

\section{Methods}

\section{Formulation of ACF Nano suspensions using $3^{2}$ factorial design}

The ACF Nano suspensions were prepared by a Nano precipitation method with a slight modification to the previously reported process. ${ }^{5}$ To prepare the Nano suspension, drug (40mg) and specific quantity of ERS PO were dissolved in $10 \mathrm{ml}$ acetone. Then the solution of the drug and polymer was poured into distilled water $(40 \mathrm{ml})$ containing specific quantity of hydrophilic surfactant PVA under constant stirring by magnetic stirrer (Remi Equipment Ltd. Mumbai, India.) at $500 \mathrm{rpm}$. The above solution was stirred continuously for $2 \mathrm{hr}$ to evaporate the solvent and the final volume of the Nano suspension was collected. The different Nano suspension formulations were prepared using a range of concentrations of surfactant $(0.1 \% \mathrm{w} / \mathrm{v}$ to $0.3 \% \mathrm{w} / \mathrm{v})$, polymer (360mg to $440 \mathrm{mg}$ ) as shown in the Tables $1-3$.

\section{Freeze drying of nanosuspension}

The optimized formulation of ACF Nano suspension was lyophilized by deep freezing using Quick freezer (Remi, Model RQFV-170) for $48 \mathrm{hr}$ at $33^{\circ} \mathrm{C}$ and then dried by using Freeze dryer (Delvac, mini lyodel) at $-80^{\circ} \mathrm{C}$ and pressure $0.100 \mathrm{mbar}$ for $48 \mathrm{hr}$. After $48 \mathrm{hr}$, sample was completely dried. Mannitol (5\% w/v) was used as a cryoprotectant in formulation before freeze drying. Lyophilized sample was collected and stored in desiccators until further study.

Table 1: Design layout of Aceclofenac Nanosuspensions (ANS) by using $3^{2}$ factorial design.

\begin{tabular}{|c|c|c|}
\hline Formulation code & $\begin{array}{c}\text { Variable } \\
\mathbf{x}_{\mathbf{1}}\end{array}$ & $\begin{array}{c}\text { Variable } \\
\mathbf{x}_{\mathbf{2}}\end{array}$ \\
\hline ANS 1 & -1 & -1 \\
\hline ANS 2 & -1 & 0 \\
\hline ANS 3 & -1 & +1 \\
\hline ANS 4 & 0 & -1 \\
\hline ANS 5 & 0 & 0 \\
\hline ANS 6 & 0 & +1 \\
\hline ANS 7 & +1 & -1 \\
\hline ANS 8 & +1 & 0 \\
\hline ANS 9 & +1 & +1 \\
\hline
\end{tabular}

Where +1 is higher level, o is mid-level and -1 is lower level for independent variable

\section{Table 2: Different factors with coded value.}

\begin{tabular}{|c|c|c|}
\hline Level & $\begin{array}{c}\mathbf{X}_{1} \text { (Drug: Polymer } \\
\text { ratio) }\end{array}$ & $\begin{array}{c}\mathbf{X}_{2} \text { (Surfactant conc. } \\
(\% \mathbf{w} / \mathbf{v})\end{array}$ \\
\hline-1 & $1: 9$ & 0.1 \\
\hline 0 & $1: 10$ & 0.2 \\
\hline+1 & $1: 11$ & 0.3 \\
\hline
\end{tabular}

\section{Table 3: Composition of final batches of ACF Nano} suspension by using $3^{2}$ factorial design.

\begin{tabular}{|c|c|c|c|}
\hline $\begin{array}{c}\text { Formulation } \\
\text { Code }\end{array}$ & $\begin{array}{c}\text { Drug } \\
\text { (ACF) } \mathbf{~ m g}\end{array}$ & $\begin{array}{c}\text { Polymer } \\
\text { (ERS PO) } \\
\text { mg }\end{array}$ & $\begin{array}{c}\text { Surfactant } \\
\text { (PVA) mg }\end{array}$ \\
\hline ANS 1 & 40 & 360 & 40 \\
\hline ANS 2 & 40 & 360 & 80 \\
\hline ANS 3 & 40 & 360 & 120 \\
\hline ANS 4 & 40 & 400 & 40 \\
\hline ANS 5 & 40 & 400 & 80 \\
\hline ANS 6 & 40 & 400 & 120 \\
\hline ANS 7 & 40 & 440 & 40 \\
\hline ANS 8 & 40 & 440 & 80 \\
\hline ANS 9 & 40 & 440 & 120 \\
\hline
\end{tabular}

\section{Evaluation of ACF nanosuspension}

The ACF Nano suspensions were further characterized for, particle size, polydispersity index, zeta potential, drug entrapment efficiency, in-vitro drug release study, $\mathrm{pH}$ study, ex-vivo trans corneal study, corneal hydration (\%) study, Fourier Transform Infrared spectroscopy (FTIR), Differential Scanning Colorimetry (DSC), X-ray Diffraction (XRD) and Scanning Electron Microscopy (SEM).

\section{Particle size, Polydispersity index and Zeta potential measurements}

The mean particle size and polydispersity index for the ACF Nano suspensions were determined by Nanoparticle Analyzer SZ-100 (Horiba Scientific, Japan). The zeta potential was determined by a laser Doppler anemometer coupled with Nanoparticle Analyzer SZ-100 (Horiba Scientific, Japan). The dispersed formulations were measured after dilution (1:100) i.e. $1 \mathrm{ml}$ formulation was dispersed in $100 \mathrm{ml} \mathrm{HPLC}$ water to produce the required count rate (50-200) to enable accurate measurement. All experiments were done in triplicate. ${ }^{16}$

\section{Determination of drug entrapment efficiency (\%)}

Entrapment efficiency of ACF Nano suspensions was determined by determining free or entrapped drug concentration in formulation by centrifugation method. ${ }^{17}$ The ACF Nano suspension $(10 \mathrm{ml})$ was centrifuged at 
$9000 \mathrm{rpm}$ at $4^{\circ} \mathrm{C}$ using the cooling centrifuge instrument (Remi C-30 Equipment's Ltd. Mumbai, India) for 45 min. The supernatant was separated out; the absorbance was recorded for the free drug content using a UV/ Visible spectrophotometer (Shimadzu 1800, Japan) at $273 \mathrm{~nm}$. The \% entrapment efficiency (EE \%) of all batches were calculated by using following equation.

$$
\text { Entrapment efficienty }(\%)=\frac{\text { Initial drug }- \text { free drug }}{\text { Initial drug }} \times 100
$$

\section{pH study}

The $\mathrm{pH}$ of ophthalmic Nano suspension formulations should be in range of 6.5 to 7.6 as at this $\mathrm{pH}$ range formulations do not cause any irritation to the patient upon administration. The $\mathrm{pH}$ of the prepared formulations was checked by using $\mathrm{pH}$ meter (Hanna instruments). ${ }^{18}$

\section{Attenuated Total Reflectance-Fourier Transform Infrared (ATR-FTIR) spectroscopy}

The infrared spectra of pure drug, polymer, physical mixture (ACF+ERS PO) in 1:1 proportion and freeze dried Nano suspension (ANS 8) was obtained using ATRFTIR spectrophotometer (Shimadzu, IRAFFINITY-1 E. Japan). The spectra were obtained for the range of 500$4000 \mathrm{~cm}^{-1} \cdot{ }^{19}$

\section{X-ray diffraction (XRD)}

The XRD studies were performed to study crystalline state characteristics of samples. The x-ray diffraction pattern of ACF, ERS PO, physical mixture (ACF+ERS $\mathrm{PO})$ in the 1:1 drug polymer ratio and freeze dried Nano suspension (ANS 8) were recorded with XPERTPRO X-ray diffractometer (Seifert and Co. D 2070, Ahrensburg) using PRS measurement program using Ni-filtered, $\mathrm{Cu} \mathrm{Ka}$ radiation with a voltage of $45 \mathrm{Kv}$ and a current of $40 \mathrm{Ma}$. The instrument was operated in the continuous scanning speed over $2 \theta$ range of $5^{\circ}$ to $40^{\circ} .{ }^{17}$

\section{Differential Scanning Calorimetry (DSC)}

The DSC spectra's of pure ACF, ERS PO, physical mixture (ACF+ERS PO) in 1:1 drug to polymer ratio and freeze dried Nano suspension (ANS 8) were obtained using differential scanning calorimeter (Shimadzu DSC 60, Japan). About $5 \mathrm{mg}$ of sample was heated in a hermetically sealed aluminum pans in the temperature range of $30^{\circ} \mathrm{C}$ to $300^{\circ} \mathrm{C}$ at a heating rate of $10^{\circ} \mathrm{C} / \mathrm{min}$. and nitrogen purge at $50 \mathrm{ml} / \mathrm{min}$. through cooling unit. ${ }^{20}$

\section{Scanning Electron Microscopy (SEM)}

The Scanning Electron Microscopy (SEM) was performed for determining the particle surface morphology and shape of Nano suspension. SEM micrographs of optimized freeze dried Nano suspension were obtained using a Hitachi scanning electron microscope (model S-2600 N, Tokyo, Japan) operating in the high-vacuum mode and an acceleration voltage of $20 \mathrm{Kv}^{21}$

\section{In vitro drug release study}

The in-vitro drug release study of $0.1 \%$ ACF solution was performed for $3 \mathrm{hr}$ and all formulations of ACF Nano suspension were performed for $8 \mathrm{hr}$ in the modified USP dissolution apparatus-1 composed of a two sided open glass cylinder. A previously soaked dialysis membrane was properly attached to the terminal part of the glass cylinder. The $2 \mathrm{ml}$ of Nano suspension was added accurately into the glass cylinder and then this glass cylinder was fixed on the stirrer of apparatus. The stirrer was dipped in $200 \mathrm{ml}$ dissolution medium of Sorenson's phosphate buffer ( $\mathrm{pH}$ 7.4) where temperature is maintained at $37^{\circ} \mathrm{C} \pm 0.5^{\circ} \mathrm{C}$ at $25 \mathrm{rpm}$ so that the dialysis membrane of cylinder end just touched the dissolution medium surface. Aliquots of $4 \mathrm{ml}$ sample were removed at different predetermined time intervals with volume replacement. The withdrawn samples were properly diluted with Sorenson's phosphate buffer ( $\mathrm{pH}$ 7.4) and analyzed for drug content, by measuring absorbance at $273 \mathrm{~nm}$ in the UV/Visible spectrophotometer (Shimadzu 1800, Japan). All the experiments were properly performed in triplicate. ${ }^{10,17}$

\section{Ex-vivo trans corneal permeation study}

Ex-vivo trans corneal permeation studies were performed using freshly excised goat corneas. The cornea was attached between receptor and donor compartments of Franz diffusion cell. The cornea was fixed in such manner that epithelial surface of cornea faced the donor cell. The area of cornea for diffusion was $0.50 \mathrm{~cm}^{2}$. Freshly prepared $20 \mathrm{ml}$ simulated tear fluid ( $\mathrm{pH}$ 7.4) was filled in the receptor compartment. All air bubbles were removed out from the compartment. An aliquot $(1 \mathrm{ml})$ of $0.1 \%$ ACF solution and optimized Nano suspension (ANS 8) separately were placed on the cornea and cover slip was kept over the opening of the donor cell to seal it; receptor medium was kept at $37^{\circ} \mathrm{C}$ temperature and stirred constantly by use of a Teflon-coated magnetic bead. This study was performed for $2 \mathrm{hr}$. After specific time interval samples were removed from receptor, diluted properly and analyzed accurately for drug content by recording absorbance at $273 \mathrm{~nm}$ in the UV/ Visible spectrophotometer (Shimadzu 1800, Japan). Results were expressed as \% permeation and amount of drug permeated which is directly related with in vitro ocular availability., ${ }^{5,17}$ The $\%$ permeation or in vitro ocular availability was calculated by following formula: 
Permeation $(\%)=\frac{\text { Amount of drug permeated in receptor }}{\text { Initial amount of drug in donor }} \times 100$

\section{Corneal hydration (\%)}

The effect of the $0.1 \%$ ACF solution and optimized ACF Nano suspension (ANS 8) on corneal hydration was determined separately. The corneal hydration study is one of the important parameter to assess any damage to corneal tissue (epithelium and/or endothelium). The tissue of sclera was removed from corneal surface at the end of experiment and its epithelial surface was cleaned and wiped with help of filter paper and weighed. The weight is considered as initial weight. Then the cornea was soaked in $1 \mathrm{ml}$ of methanol, properly dried overnight at temperature of $90^{\circ} \mathrm{C}$ and reweighed. Reweighed weight was considered as final weight. From the difference between initial and final weight, \% corneal hydration was calculated by following formula. ${ }^{5}$

$$
\% \text { Corneal hydration }=\frac{(\text { Initial weight }- \text { Final weight })}{(\text { initial weight })} \times 100
$$

\section{Drug release kinetics modeling}

The kinetics of ACF release from Nano suspension was determined by using various release kinetics and the drug release mechanism as like zero order kinetics, first order kinetics, Higuchi model, Hixson-crowell model and Korsmeyer-Peppas model. The release data were obtained by calculating various parameters. The parameters exponent coefficient (n) and regression coefficient $\left(\mathrm{R}^{2}\right)$ were determined by equation of Korsmeyer-Peppas model to understand the drug release mechanism. The model which best fits the drug release data was choosed based on the $R^{2}$ value in different models. The model that gives high $\mathrm{R}$ value was considered as best fit model. ${ }^{16,22}$

\section{Comparative study of optimized ACF nanosuspension with standard ACF solution}

The optimized ACF nanosuspension was compared with standard ACF solution prepared according to USP and was further evaluated for in vitro drug release, ex-vivo trans corneal permeation study and corneal hydration $(\%)$.

\section{Preparation of $0.1 \%$ ACF solution $\mathrm{pH}$ (7.2)}

ACF solution of $0.1 \%(\mathrm{w} / \mathrm{v} \mathrm{pH} 7.2)$ concentration was made into isotonic phosphate buffer according to USP. The required quantity of drug was properly dissolved in
$100 \mathrm{ml}$ isotonic phosphate buffer $\mathrm{pH} 7.2$ to have $0.1 \%$ $(\mathrm{w} / \mathrm{v})$ concentration. ${ }^{23}$

\section{RESULTS AND DISCUSSION} Particle size, Zeta potential measurements and
Polydispersity index of ACF Nano suspension

\section{Particle size}

The appearance of bluish opalescence color in Nano suspension revealed that the formulation was in nanometers range. The particle size of ANS formulations was observed in between $74.9 \pm 9.6 \mathrm{~nm}$ to $88.9 \pm 14.7 \mathrm{~nm}$ (Table 4). The smallest particle size was observed with ANS 7 whereas ANS 3 showed largest particle size. The results showed that drug to polymer ratio does not have significant impact on mean particle size but it was observed that increase in the Concentration of PVA increased mean particle size of all Nano suspensions except ANS 4. The role of stabilizer in the nanoparticles preparation is longterm physical stabilization of nanoparticles. It attaches to the surface of particles and prevents aggregation of particles. The positive effect of PVA concentration on particle size was observed. The reason behind this is, the increased concentration of PVA affects the viscosity of formulations. Increased viscosity of formulations due to the increase in PVA concentration may result in formation of larger nanoparticles. The mean particle size of optimized batch (ANS 8) was 77.1 $13.9 \mathrm{~nm}$. All batches showed a small mean size (below 500nm), suitable for possible ocular application. In trial studies, particle size increases with the polymer concentration due to the steep difference of polymer concentration among batches, but in final batches the negative effect of drug polymer- ratio on particle size observed due to the less difference of polymer concentration among batches and may be due to the presence of interaction of stabilizer in formulation.

\section{Effect of independent variables on particle size using $3^{2}$ factorial design}

The factorial design suggested a linear model for the effect of particle size. The relationship between the coded factors and particle size was studied using equation 1 and 3D plots (Figure 1).

$$
\text { Particle size }=80.08-3.02 \mathrm{~A}+2.38 \mathrm{~B}(1)
$$

As per the ANOVA results (Table 5) for optimization process, the model F-value of 7.84 was obtained, which suggested that model is significant. There is only a $2.12 \%$ chance that an $F$-value this large could occur because of noise. $P$-value is less than 0.0500 for $\mathrm{A}$ and $\mathrm{B}$ which 


\begin{tabular}{|c|c|c|c|c|c|c|c|}
\hline \multirow{2}{*}{$\begin{array}{l}\text { Batch } \\
\text { code }\end{array}$} & \multicolumn{2}{|c|}{ Formulation variables } & \multicolumn{5}{|c|}{ Formulation response } \\
\hline & $\begin{array}{l}\text { Drug: Polymer } \\
\text { ratio }\end{array}$ & $\begin{array}{c}\text { Conc. of PVA } \\
(\% \mathrm{w} / \mathrm{v})\end{array}$ & $\begin{array}{l}\text { Particle size } \\
\quad(\mathrm{nm})\end{array}$ & $\begin{array}{l}\text { Zeta potential } \\
(\mathrm{mV})\end{array}$ & $\begin{array}{l}\text { Polydispersity } \\
\text { index }\end{array}$ & $\begin{array}{l}\text { Entrapment } \\
\text { efficiency (\%) }\end{array}$ & $\mathrm{pH}$ \\
\hline ANS 1 & $1: 9$ & 0.1 & $79.4+11.3$ & $34+3.30$ & $0.351+0.01$ & $72.62+0.91$ & $6.43+0.04$ \\
\hline ANS 2 & $1: 9$ & 0.2 & $82.1+9.2$ & $41.6+4.82$ & $0.391+0.04$ & $70.50+0.44$ & $6.66+0.04$ \\
\hline ANS 3 & $1: 9$ & 0.3 & $88.9+14.7$ & $35.5+2.96$ & $0.322+0.06$ & $74.74+0.83$ & $6.50+0.00$ \\
\hline ANS 4 & $1: 10$ & 0.1 & $80.3+19.6$ & $29.9+4.18$ & $0.337+0.08$ & $80.25+0.36$ & $7.06+0.04$ \\
\hline ANS 5 & $1: 10$ & 0.2 & $78+6.8$ & $35.1+6.03$ & $0.358+0.05$ & $75.59+0.42$ & $6.80+0.04$ \\
\hline ANS 6 & $1: 10$ & 0.3 & $79.7+21.5$ & $27+1.50$ & $0.303+0.02$ & $77.71+0.17$ & $6.90+0.00$ \\
\hline ANS 7 & $1: 11$ & 0.1 & $74.9+9.6$ & $31+4.68$ & $0.351+0.01$ & $86.18+0.81$ & $7.23+0.04$ \\
\hline ANS 8 & $1: 11$ & 0.2 & $77.1+13.9$ & $34.3+1.70$ & $0.312+0.09$ & $91.27+0.11$ & $7.30+0.00$ \\
\hline ANS 9 & $1: 11$ & 0.3 & $80.3+17.8$ & $30.3+3.12$ & $0.350+0.04$ & $89.57+0.76$ & $7.20+0.00$ \\
\hline
\end{tabular}

(Mean $\pm S E, n=3$ ).

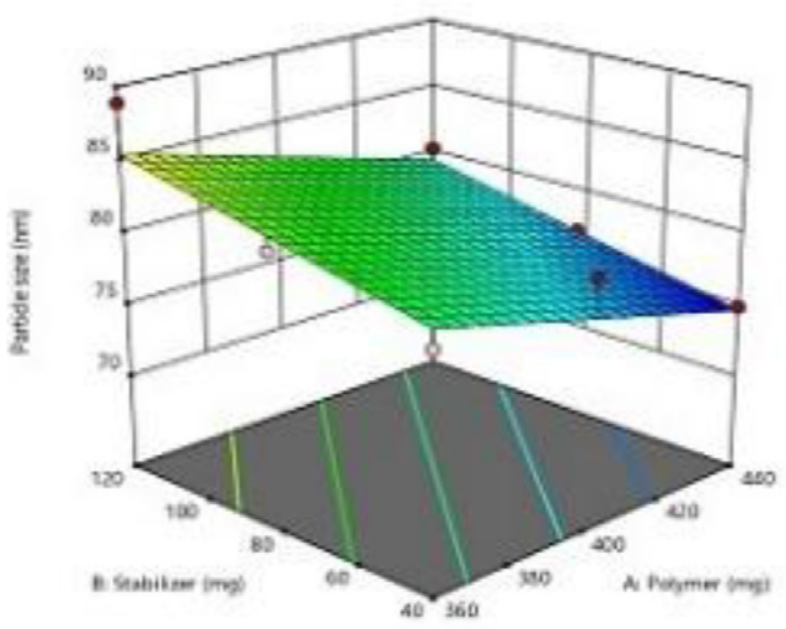

Figure 1: Response surface plot of the effect of independent variables on particle size.

indicated that model terms are significant. Based on the equation, it can be found that polymer (A) had negative coefficient whereas the value of coefficient for stabilizer (B) was positive. The negative sign for the coefficient of polymer indicated that the particle size decreases with increase in polymer concentration. The positive sign for the coefficient of stabilizer indicated that the particle size increases as the concentration of stabilizer increases. The graph (Figure 1) also revealed that as polymer concentration increases particle size decreases and as stabilizer concentration increases particle size also increases.

\section{Zeta potential}

The zeta potential is an important surface characterization method which gives information related to the surface charge of nanoparticles. The magnitude of zeta potential indicates the potential stability of

\begin{tabular}{|c|c|c|c|c|c|}
\hline Variables & $F$-value & $p$-value & $R^{2}$ & $R^{2}$ adj. & \multirow{4}{*}{ Significant } \\
\hline Model & 7.84 & 0.0212 & \multirow{3}{*}{0.7233} & \multirow{3}{*}{0.6310} & \\
\hline$A$ & 9.65 & 0.0209 & & & \\
\hline B & 6.03 & 0.0495 & & & \\
\hline
\end{tabular}

Nano particulate system. The zeta potential values of Nano suspension containing ERS PO was found in between $27.5 \pm 1.50 \mathrm{mV}$ to $41.6 \pm 4.82 \mathrm{mV}$ as shown in Table 4. Zeta potential of optimized batch (ANS 8) was found to be $34.3 \pm 1.70 \mathrm{mV}$, positive zeta potential values were obtained which might be due to the positive surface charge of the Eudragit RS PO. All other ANS formulations showed positive zeta potential (Figure 2). As corneal surface possesses negative charge, the positive charge on nanoparticles could help in efficient adhesion to the corneal surface which in turn would enhance bioavailability of ocular drugs.

\section{Effect of independent variables on zeta potential using $3^{2}$ factorial design}

The factorial design suggested a quadratic model for the effect of zeta potential. The relationship between the coded factors and zeta potential was studied using equation 2 and 3D plots (Figure 3).

$$
\begin{aligned}
\text { Zeta potential }= & 34.48-2.58 \mathrm{~A}-0.3500 \mathrm{~B}- \\
& 0.5500 \mathrm{AB}+3.78 \mathrm{~A}^{2}-5.72 \mathrm{~B}^{2}
\end{aligned}
$$

As per the ANOVA results (Table 6) for optimization process, the model $F$-value of 10.31 was obtained, which suggested that model is significant. There is only a $4.17 \%$ chance that an $F$-value this large could occur because of noise. $P$-value is less than 0.0500 which indicated that model terms are significant. From an equation, the main effects (A-polymer and B-stabilizer), 


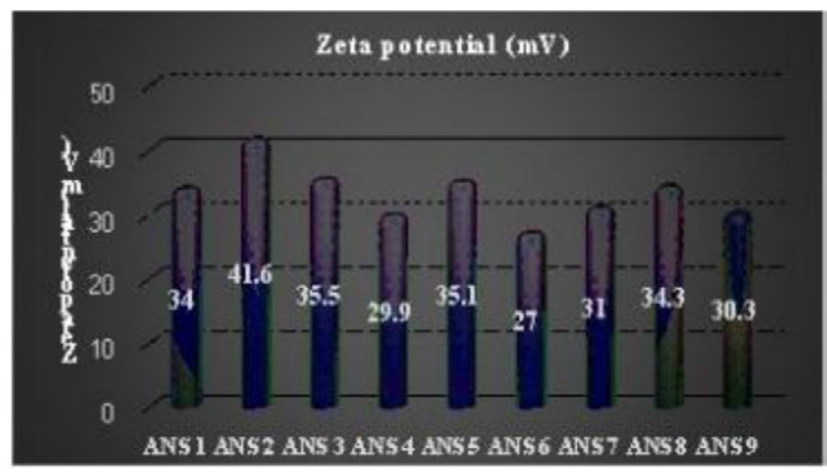

Figure 2: Graphical representation of Zeta potential $(\mathrm{mV})$ of ACF nanosuspension.

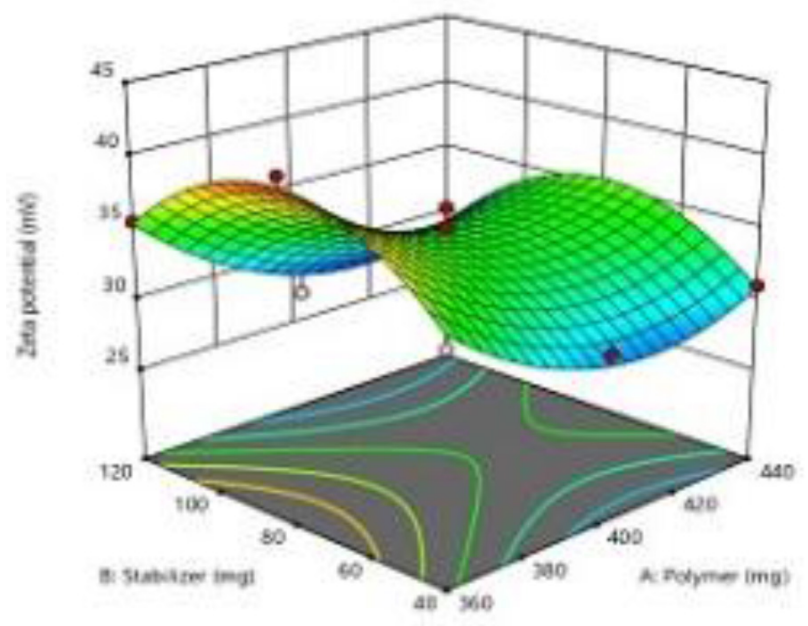

Figure 3: Response surface plot of the effect of independent variables on zeta potential.

interactive effect $(\mathrm{AB})$ and quadratic effects $\left(\mathrm{A}^{2}\right.$ and $\left.\mathrm{B}^{2}\right)$ were observed. From these effects, only $A, A^{2}$ and $B^{2}$ are significant $(P<0.0500)$ which played an important key role in influencing zeta potential of formulations. In the main effects both $\mathrm{A}$ (polymer) and $\mathrm{B}$ (stabilizer) individually showed negative effect on zeta potential, i.e. the increase in concentration of both polymer and stabilizer lead to decrease in the zeta potential values amongst which polymer had strong effect on zeta potential as compared to stabilizer, also the polymer and stabilizer combinely showed negative impact on zeta potential, the graph and higher order equation reflected an interaction/ combined effect of $\mathrm{A}$ and $\mathrm{B}$ on zeta potential of Nano suspension.

\section{Polydispersity index}

The polydispersity index (PDI) values indicate the particle size distribution. It also suggests the stabilization of formulation. PDI values were obtained in the range of 0.01 to 0.5 as shown in Table 4, which demonstrates narrow size distribution, while PDI above 0.7 indicates
Table 6: Result of ANOVA for zeta potential.

\begin{tabular}{|c|c|c|c|c|c|}
\hline Variables & F-value & $p$-value & $R^{2}$ & $R^{2}$ adj. & \multirow{7}{*}{ 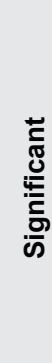 } \\
\hline Model & 10.31 & 0.0417 & \multirow{6}{*}{0.9450} & \multirow{6}{*}{0.8533} & \\
\hline A & 15.18 & 0.0300 & & & \\
\hline B & 0.2786 & 0.6342 & & & \\
\hline$A B$ & 0.4587 & 0.5468 & & & \\
\hline$A^{2}$ & 10.85 & 0.0459 & & & \\
\hline$B^{2}$ & 24.78 & 0.0156 & & & \\
\hline
\end{tabular}

very broad size distribution. The polydispersity index of all formulations containing ERS PO varies from $0.303 \pm 0.02$ to $0.391 \pm 0.04$. The optimized Nano suspension (ANS 8) provides $0.312 \pm 0.09$ PDI. Particle size distribution of all the formulations were found to be of narrow size range (Figure 4) and well suited for ocular use.

\section{Drug Entrapment Efficiency (\%)}

Drug entrapment efficiency (\%) of the ERS PO based ACF Nano suspensions were found to be in between $70.50 \pm 0.44 \%$ to $91.27 \pm 0.11 \%$ as shown in Table 4 . As the drug-polymer ratio increases the $\%$ drug entrapment efficiency (\%) also get increased. The optimized formulation (ANS 8) showed $91.27 \pm 0.11 \%$ highest drug entrapment efficiency. (Figure 5)

\section{Effect of independent variables on entrapment efficiency (\%) using $3^{2}$ factorial design}

The factorial design suggested a linear model for the effect of entrapment efficiency (\%). The relationship between the coded factors and \% entrapment efficiency was studied using equation 3 and 3D plots (Figure 6).

Entrapment efficiency $(\%)=79.83+8.19 \mathrm{~A}+$

$$
0.4950 \mathrm{~B}
$$

As per the ANOVA results (Table 7) for optimization process, the model $F$-value of 24.55 was obtained, which suggested that model is significant. There is only a $0.13 \%$ chance that an F-value this large could occur

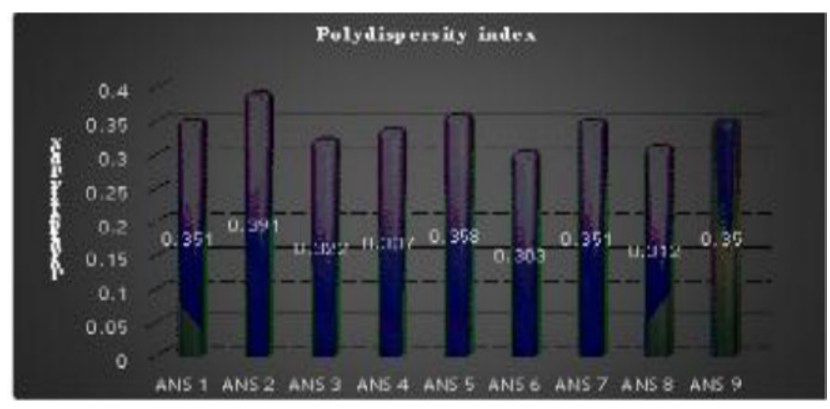

Figure 4: Graphical representation of PDI of ACF nanosuspension. 


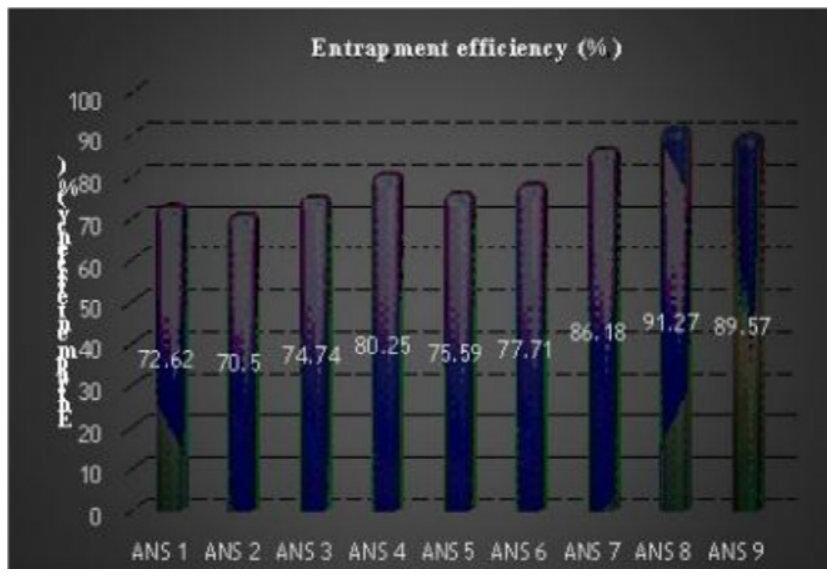

Figure 5: Graphical representation of Entrapment efficiency (\%) of ACF nanosuspensions.

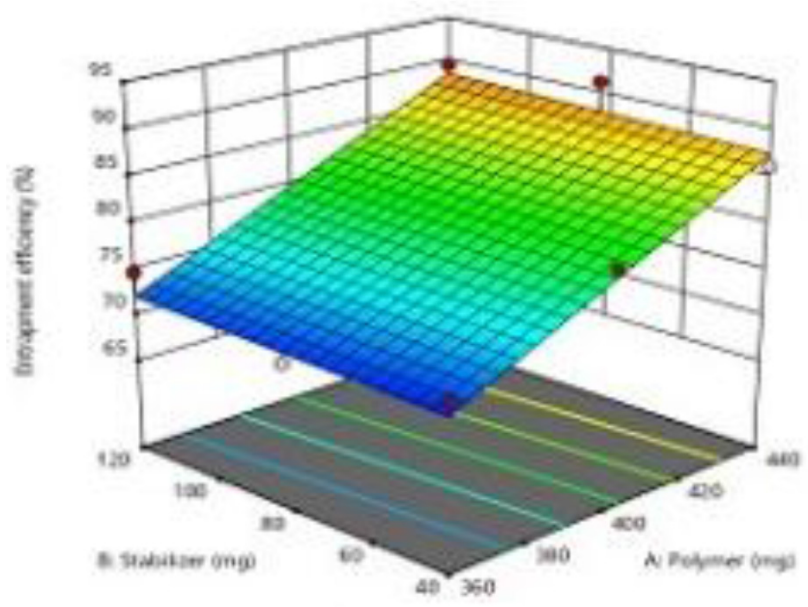

Figure 6: Response surface plot of the effect of independent variables on $\%$ entrapment efficiency.

because of noise. $P$-value is less than 0.0500 which indicated that model terms are significant. Based on the equation, it can be found that polymer (A) and stabilizer (B) had positive coefficient but only $\mathrm{A}$ is significant $(P<0.0500)$. The positive sign for the coefficient of a (polymer) indicated that the entrapment efficiency increases with increase in concentration of polymer. From graph (Figure 6) it is revealed that stabilizer has constant effect on entrapment efficiency while entrapment efficiency increases with increase in polymer concentration.

\section{pH}

$\mathrm{pH}$ is the most important parameter considered in the formulation process. The $\mathrm{pH}$ value of ocular Nano suspension should be such that the Nano suspension formulation will be stable at that $\mathrm{pH}$ value and it would not cause irritation to the patient upon administration.

\begin{tabular}{|c|c|c|c|c|c|}
\hline Variables & F-value & $p$-value & $R^{2}$ & $R^{2}$ adj. & \multirow{4}{*}{ 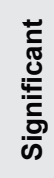 } \\
\hline Model & 24.55 & 0.0013 & \multirow{3}{*}{0.8911} & \multirow{3}{*}{0.8548} & \\
\hline A & 48.92 & 0.0004 & & & \\
\hline B & 0.1786 & 0.6873 & & & \\
\hline
\end{tabular}

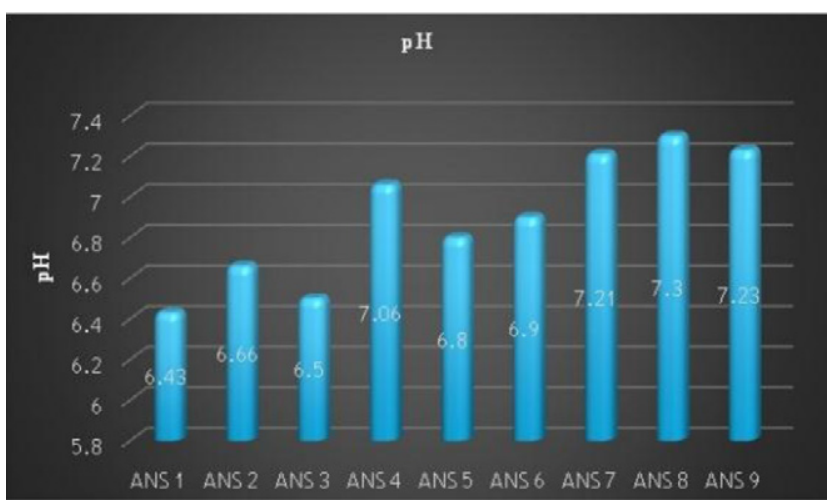

Figure 7: Graphical representation of $\mathrm{pH}$ of ACF nanosuspensions.

The optimized batch showed $\mathrm{pH} 7.3 \pm 0.00$. The acceptable $\mathrm{pH}$ range $6.43 \pm 0.04$ to $7.3 \pm 0.00$ was observed (Figure 7 and Table 4) and hence it is predicted that formulation would not cause irritation to the eye upon administration. It was also observed that increase in Eudragit RS PO polymer causes a slight increase in $\mathrm{pH}$ for formulations.

\section{ATR-FTIR spectra}

IR spectras of ACF, Eudragit RS PO, Physical mixture, ANS 8 were obtained as shown in Figure 8. IR spectrum of optimized formulation (ANS 8) showed the characteristic peak of Eudragit RS PO at $3385.07 \mathrm{~cm}^{-1}$ (O-H stretching), $1726.29 \mathrm{~cm}^{-1}$ ( $\mathrm{C}=$ O stretching for ester), $1238.30 \mathrm{~cm}^{-1}$ (C-O stretching) and peaks of mannitol at $3277.06 \mathrm{~cm}^{-1}$ (O-H stretching) and 2985.81, $2941.44 \mathrm{~cm}^{-1}$ (C-H stretching). There is no peak observed for ACF which might be due to drug is present in amorphous form in formulation.

\section{X-ray diffraction (XRD)}

In order to study the physical nature of pure drug, polymer, physical mixture and encapsulated drug, the $\mathrm{X}$-ray diffraction (XRD) was used. The XRD pattern of the ACF was showed in (Figure 9). It was observed that the pattern of the ACF exhibited intense crystalline peaks at $11.53^{\circ}, 18.56^{\circ}, 22.33^{\circ}, 24.54^{\circ}, 25.61^{\circ}$ and $32.23^{\circ}$ $2 \theta$, which proved that the ACF was in crystalline form. 


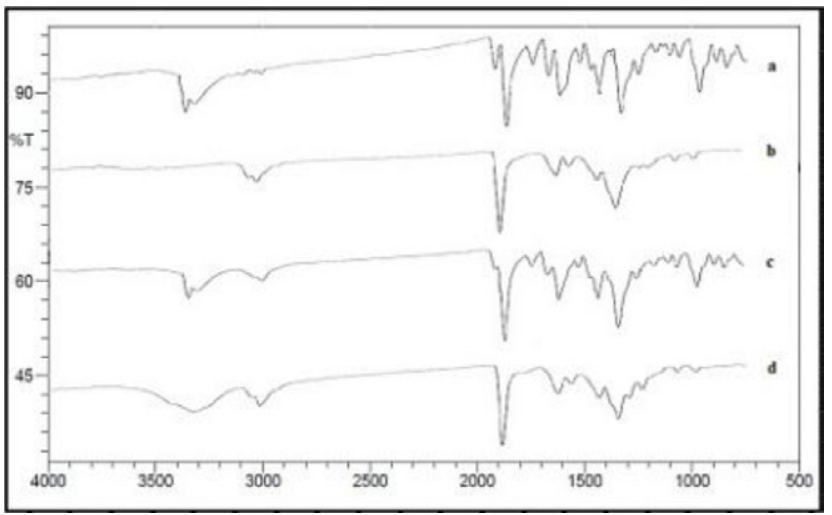

Figure 8: ATR-FTIR layout of a) ACF, b) Eudragit RS PO, c) Physical mixture (ACF+ ERS PO), d) ANS 8.

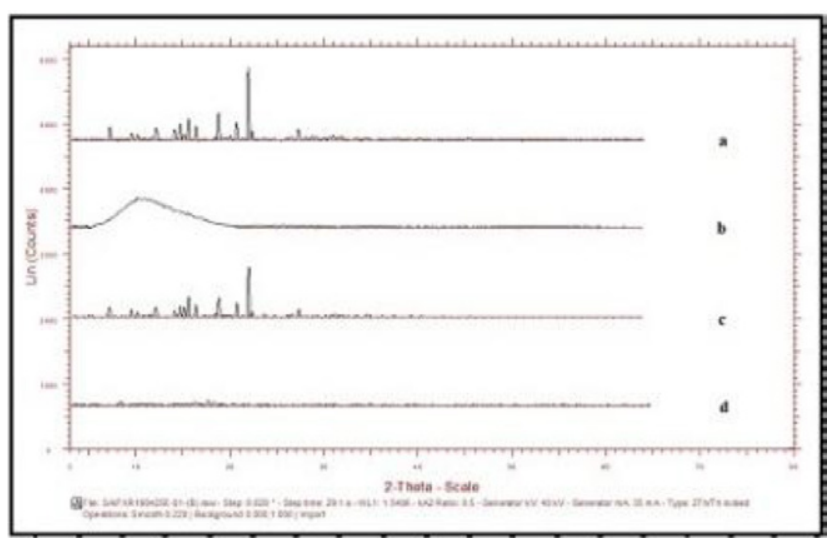

Figure 9: XRD layout of a) ACF b) Eudragit RS PO c) Physical mixture (ACF + ERS PO), d) ANS 8.

From the XRD patterns of Eudragit RS PO, it is clear that it is completely amorphous in nature as there are no sharp peaks observed which was showed in (Figure 9). The XRD patterns of physical mixture (ACF+ERS PO) exhibited characteristics peaks of ACF at $11.50^{\circ}, 18.55^{\circ}$, $22.32^{\circ}, 24.53^{\circ}$ and $32.18^{\circ} 2 \theta$. This result indicates that physical blending did not affect the drug diffraction (as shown in Figure 9). The XRD pattern of eudragit RS PO based ACF Nano suspension showed peaks of mannitol, no sharp intense peaks of ACF observed, which suggests that drug is changed from its crystalline form to amorphous form in the formulation which is indication of enhanced solubility of ACF (as shown in Figure 9).

\section{Differential Scanning Calorimetry (DSC)}

From DSC study, it has been observed that ACF is crystalline in nature. It exhibit sharp melting endotherm at temperature of $153.51^{\circ} \mathrm{C}$. (Figure 10). The thermal characteristics peak of Eudragit RS PO is observed as a broad melting endotherm at $82.42^{\circ} \mathrm{C}$. (Figure 10). The physical mixture of ACF and Eudragit RS PO showed characteristic peak at $96.77^{\circ} \mathrm{C}$ and depressed

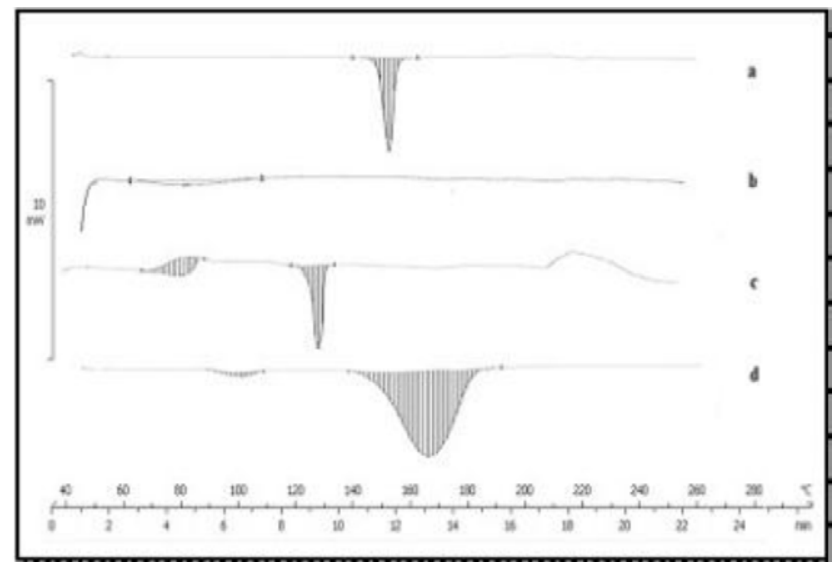

Figure 10: DSC layout of a) ACF, b) Eudragit RS PO, c) Physical mixture (ACF+ERS PO), d) ANS 8.

endotherm of drug at $130.57^{\circ} \mathrm{C}$. (Figure 10). The DSC spectra of lyophilized formulation of ANS 8 showed endothermic peak at $166.26^{\circ} \mathrm{C}$ and $101.89^{\circ} \mathrm{C}$ (Figure 10) may be due to presence of mannitol and eudragit RS PO respectively. There is no peak observed for ACF in DSC spectra of formulation which might be due to drug is present in amorphous form in the formulation.

\section{Scanning Electron Microscopy (SEM)}

Morphological evaluation of optimized ACF Nano suspension formulation was performed using Scanning Electron Microscopy (SEM). The SEM study of lyophilized powder was carried out. SEM images of optimized Nano suspension (ANS 8) lyophilized powder of optimized batch was taken at different magnification power i.e. X500, X1500, X3500 and X7000 and all images was showed in Figure 11. The rough and granular surface was appeared at low magnification power is of fluffy lyophilized powder. The SEM images suggests that the particles of ACF Nano suspension were found to be small in size $(75.90 \mathrm{~nm}, 72.16 \mathrm{~nm})$ and has a spherical shape with smooth surface of powdered particles that suggesting possible stabilization of nanoparticles. Nano suspensions will possibly does not cause any irritation into eye after administration, as it is already stated that isometric particles of thick edges and angles cause less irritation than particles of sharp edges and angles.

\section{In vitro drug release study}

In vitro drug release study was carried out for all formulation by using dialysis membrane in Sorenson's phosphate buffer solution $(\mathrm{pH}$ 7.4) as the release medium. The release profile of all formulation and the percentage drug release versus time profile are depicted in Table 8. 


\section{In vitro drug release kinetics}

The drug release data which is obtained from in vitro drug dissolution experiment was subjected to various kinetic

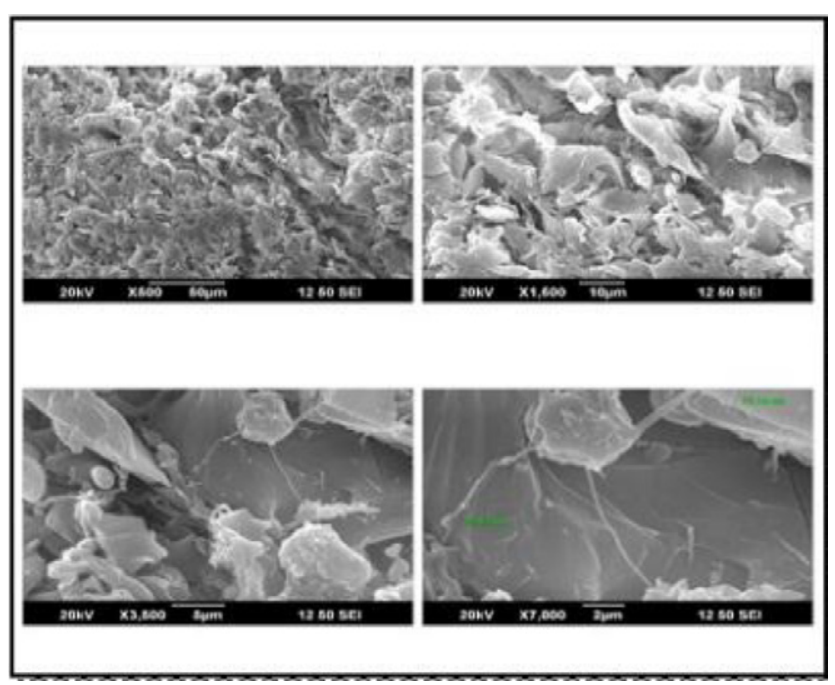

Figure 11: SEM images of lyophilized nanosuspension. equations to evaluate the drug release mechanism and kinetics. The in vitro drug release data were fitted into various kinetic equations; zero order release kinetics, first order release kinetics, Higuchi model, Hixson-crowell model and Korsmeyer-Peppas equation. The in vitro drug release data fitting values are showed in Table 9. In vitro drug release is best explained by Korsmeyer-Peppas equation. The $R^{2}$ values of Korsmeyer-Peppas equation were close to 1 . The diffusion coefficient values of Korsmeyer-Peppas equation of all formulation batches ranged from 0.5811 to 0.8973 . Thus it was concluded that the values of $n$ (slope) for all formulation batches as per Korsmeyer-Peppas equation were found to be in between 0.5 to 1 which indicate that the drug release from the Nano suspensions follows Anomalous (nonFickian) diffusion mechanism, i.e. contributed by combination of dissolution and diffusion. According to the correlation coefficients $\left(R^{2}\right)$ of all formulations at 8 $\mathrm{hr}$ measurements, the release patterns were best fitted to the Higuchi-square-root release kinetics model.

\begin{tabular}{|c|c|c|c|c|c|c|c|c|c|}
\hline \multirow{2}{*}{$\begin{array}{l}\text { Time } \\
\text { (hrs) }\end{array}$} & \multicolumn{9}{|c|}{$\%$ Cumulative drug release. } \\
\hline & ANS 1 & ANS 2 & ANS 3 & ANS 4 & ANS 5 & ANS 6 & ANS 7 & ANS 8 & ANS 9 \\
\hline 0.5 & $10.42+0.70$ & $13.81+1.02$ & $9.57+0.51$ & $7.03+0.53$ & $11.69+0.33$ & $8.30+0.83$ & $5.33+0.79$ & $7.45+0.21$ & $7.03+0.39$ \\
\hline 1 & $19.74+0.31$ & $25.25+0.51$ & $22.28+0.43$ & $18.89+0.45$ & $21.01+0.54$ & $14.23+0.23$ & $12.96+0.11$ & $15.08+0.21$ & $12.11+0.12$ \\
\hline 2 & $26.94+0.20$ & $35.84+1.01$ & $34.57+0.48$ & $28.64+0.68$ & $37.54+0.17$ & $24.40+0.87$ & $20.59+0.45$ & $25.67+0.43$ & $19.32+0.41$ \\
\hline 3 & $35.42+0.37$ & $42.62+0.10$ & $44.32+0.70$ & $38.38+0.55$ & $41.35+0.53$ & $33.30+0.64$ & $29.91+0.51$ & $34.57+0.35$ & $28.22+0.66$ \\
\hline 4 & $45.16+0.88$ & $50.67+0.57$ & $52.79+0.66$ & $46.44+0.47$ & $53.64+0.51$ & $42.62+0.28$ & $39.23+0.49$ & $42.20+0.23$ & $35.00+0.75$ \\
\hline 5 & $51.10+0.58$ & $56.61+0.20$ & $58.72+0.38$ & $53.64+0.25$ & $57.45+0.79$ & $49.83+0.13$ & $50.67+0.15$ & $47.28+0.37$ & $44.74+0.71$ \\
\hline 6 & $58.30+0.40$ & $64.23+0.36$ & $62.11+0.30$ & $58.30+0.42$ & $60.42+0.27$ & $57.45+0.67$ & $59.15+0.35$ & $54.91+0.40$ & $52.79+0.22$ \\
\hline 7 & $63.38+1.26$ & $70.59+0.13$ & $67.22+0.50$ & $61.27+0.85$ & $64.23+0.38$ & $62.11+0.48$ & $60.00+0.64$ & $57.88+0.83$ & $59.57+0.45$ \\
\hline 8 & $69.74+0.73$ & $74.40+0.41$ & $71.86+0.71$ & $65.50+0.47$ & $70.59+0.31$ & $67.20+0.37$ & $66.77+0.47$ & $61.27+0.54$ & $63.38+0.18$ \\
\hline
\end{tabular}

(Mean $\pm \mathrm{SE}, n=3$ ).

\begin{tabular}{|c|c|c|c|c|c|c|c|}
\hline \multirow[t]{2}{*}{$\begin{array}{l}\text { Batch } \\
\text { code }\end{array}$} & \multirow[t]{2}{*}{$\begin{array}{c}\text { Zero order } \\
R^{2}\end{array}$} & \multirow[t]{2}{*}{$\begin{array}{c}\text { First order } \\
\qquad R^{2}\end{array}$} & \multirow{2}{*}{$\begin{array}{c}\text { Higuchi } \\
\text { model } \\
R^{2}\end{array}$} & \multirow[t]{2}{*}{$\begin{array}{l}\text { Hixson-crowell } \\
\text { model } R^{2}\end{array}$} & \multicolumn{2}{|c|}{$\begin{array}{c}\text { Koresmeyer- } \\
\text { Peppas }\end{array}$} & \multirow[t]{2}{*}{ Diffusion mechanism } \\
\hline & & & & & $R^{2}$ & $\begin{array}{c}N \\
\text { (slope) }\end{array}$ & \\
\hline ANS 1 & 0.9856 & 0.9961 & 0.9943 & 0.9976 & 0.9936 & 0.6640 & Anomalous (non-Fickian) diffusion \\
\hline ANS 2 & 0.9718 & 0.9951 & 0.9967 & 0.9941 & 0.9900 & 0.5811 & Anomalous (non-Fickian) diffusion \\
\hline ANS 3 & 0.9346 & 0.9893 & 0.9906 & 0.9765 & 0.9669 & 0.6865 & Anomalous (non-Fickian) diffusion \\
\hline ANS 4 & 0.9442 & 0.9876 & 0.9929 & 0.9767 & 0.9637 & 0.7588 & Anomalous (non-Fickian) diffusion \\
\hline ANS 5 & 0.9252 & 0.9769 & 0.9826 & 0.9644 & 0.9764 & 0.6281 & Anomalous (non-Fickian) diffusion \\
\hline ANS 6 & 0.9847 & 0.9992 & 0.9955 & 0.9983 & 0.9990 & 0.7651 & Anomalous (non-Fickian) diffusion \\
\hline ANS 7 & 0.9792 & 0.9886 & 0.9848 & 0.9889 & 0.9905 & 0.8973 & Anomalous (non-Fickian) diffusion \\
\hline ANS 8 & 0.9626 & 0.9925 & 0.9975 & 0.9854 & 0.9892 & 0.7508 & Anomalous (non-Fickian) diffusion \\
\hline ANS 9 & 0.9946 & 0.9916 & 0.9807 & 0.9958 & 0.9971 & 0.8088 & Anomalous (non-Fickian) diffusion \\
\hline
\end{tabular}


Table 10: In vitro drug release study of ANS 8 and $0.1 \%(w / v)$ ACF solution $\mathrm{pH} 7.2$.

\begin{tabular}{|c|c|c|}
\hline Time (hours) & ANS 8 & $\mathbf{0 . 1} \% \mathbf{~ ( w / v ) ~ A C F ~ s o l u t i o n ~}$ \\
\hline 0.5 & $7.45+0.21$ & $47.71 \pm 0.42$ \\
\hline 1 & $15.08+0.21$ & $77.79 \pm 0.21$ \\
\hline 2 & $25.67+0.43$ & $91.35 \pm 0.65$ \\
\hline 3 & $34.57+0.35$ & $98.55 \pm 0.28$ \\
\hline 4 & $42.20+0.23$ & - \\
\hline 5 & $47.28+0.37$ & - \\
\hline 6 & $54.91+0.40$ & - \\
\hline 7 & $57.88+0.83$ & - \\
\hline 8 & $61.27+0.54$ & - \\
\hline
\end{tabular}

(Mean $\pm \mathrm{SE}, n=3$ ).

Table 11: Ex-vivo transcorneal study of ANS 8 and $0.1 \%(w / v)$ ACF solution pH 7.2.

\begin{tabular}{|c|c|c|}
\hline Formulation & $\begin{array}{c}\text { \% corneal permeation } \\
\text { (2 hrs) }\end{array}$ & $\begin{array}{c}\text { \% corneal } \\
\text { hydration }\end{array}$ \\
\hline $0.1 \%$ ACF solution & 3.91 & 72.97 \\
\hline ANS 8 & 7.39 & 76.24 \\
\hline
\end{tabular}

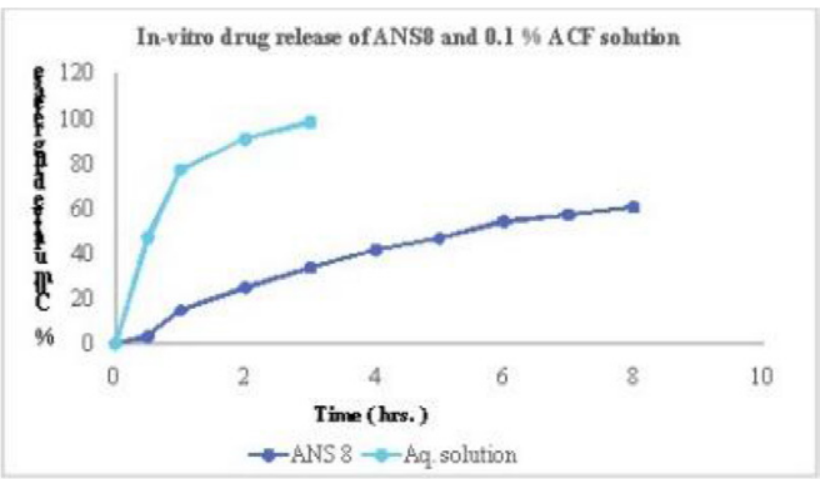

Figure 12: In vitro drug release study of ANS 8 and $0.1 \%$ ACF solution.

\section{Evalutionary Comparison of $0.1 \%$ (w/v) ACF solution pH 7.2 with optimized ACF Nano suspension (ANS 8) \\ In-vitro drug release study}

From the in-vitro drug release study, it is observed that the optimized ACF Nano suspension (ANS 8) showed $7.45 \pm 0.21 \%$ drug release in $0.5 \mathrm{hrs}$ and $61.27 \pm 0.54$ $\%$ release in $8 \mathrm{hr}$ while $0.1 \%$ ACF solution showed $47.71 \pm 0.42 \%$ drug release in $0.5 \mathrm{hr}$ and $98.55 \pm 0.28 \%$ release in $3 \mathrm{hr}$ From results obtained, it is indicated that ACF Nano suspension showed sustained drug release profile as compare to $0.1 \% \mathrm{ACF}$ solution. The release profile of formulations and the percentage drug release versus time profile are depicted in Table 10 and showed in Figure 12 respectively. By studying literature, it is

\section{Comealpermeation and $\%$ comeal hydration study}

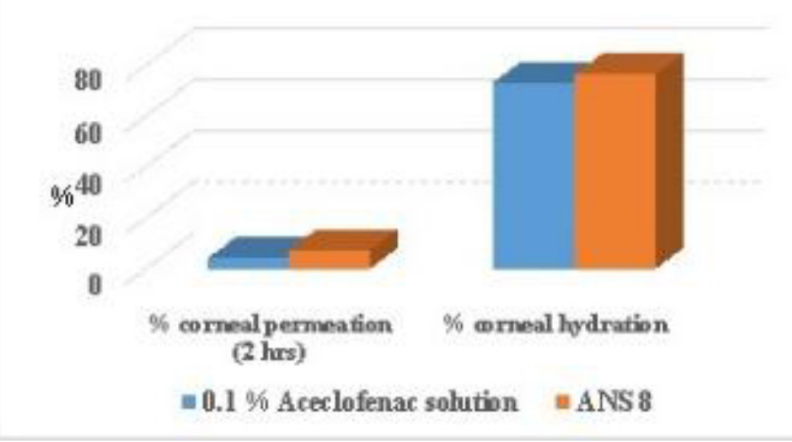

Figure 13: Graphical representation of ex vivo transcorneal permeation study.

found that drug release studies for ophthalmic forms was carried out even if it is present in the solution form for comparison with the prepared formulation. Here drug release from $0.1 \%$ ACF solution showed drug release extended for $3 \mathrm{hr}$. Aceclofenac belongs to BCS class-II that may be one of the reasons for the same. Even if drug is already dissolved it is possible because it first diffuses through cellophane membrane (accepted dissolution method in literature) and then comes in contact with the dissolution medium. The time required for solution to diffuse through cellophane membrane and its interaction with the dissolution media are considered as $3 \mathrm{hr}$ extended release time from $0.1 \%$ ACF solution.

\section{Ex- vivo transcorneal permeation and \% corneal hydration study}

From ex-vivo trans corneal study, a 2-fold increase in permeation of ACF from ANS 8 was observed when compared to the $0.1 \%$ ACF solution across goat cornea as shown in Table 11 and Figure 13. ACF showed 7.39 $\%$ in vitro ocular availability as $\%$ permeation is directly related with in vitro ocular availability. The corneal hydration (\%) remained in normal range that is 75 to 80 $\%$ which indicated the eye friendly behavior of optimized formulation. The positively charged nanoparticles due to eudragit RS PO polymer interacts with the negatively charged cornea which is responsible for mucoadhesion and increase in the retention time of nanoparticles. The higher permeation from the nanoparticles as compared to the solution may be because of retention and depot of nanoparticles on the corneal surface due to mucoadhesion.

\section{CONCLUSION}

The present investigation highlighted the successful formulation and characterization of ocular delivery of Aceclofenac through Eudragit RS PO based Nano 
suspension. The Nano suspensions were prepared successfully by using Nano precipitation method which is easiest and most reproducible method to prepare Nano suspension without need of any sophisticated instruments. The FTIR, DSC and XRD studies confirmed that there was no drug-polymer interaction. From DSC and XRD study, the amorphization of drug in formulation was observed from which it can be predicted that solubility of drug could be enhanced. The small particle size, narrow size distribution and $\mathrm{pH}$ within normal range for all prepared Nano suspensions were observed which is acceptable for ocular administration. All formulations showed positive zeta potential from which it is be expected that formulation could interact with anionic cornea and increases residence time. The SEM images revealed that there will be no irritation cause after ocular administration due to spherical and smooth surface. The results of in vitro drug release study indicated that higher $\%$ entrapment efficiency of drug in Nano suspension delays the drug release and increase the corneal residence time. From ex vivo trans corneal study it was found that optimized formulation showed higher $\%$ permeation of drug as compared with $0.1 \%$ Aceclofenac solution with no signs of corneal damage and eye friendly behavior.

\section{ACKNOWLEDGEMENT}

The authors are thankful to the management of Gourishankar Institute of Pharmaceutical Education and Research, Limb, Satara for providing excellent research facilities. Also authors are grateful to Shivaji University, Kolhapur for providing the Sophisticated Analytical Instrumentation Facility (SAIF) of Shivaji University.

\section{CONFLICT OF INTEREST}

The authors declare no conflicts of interest.

\section{ABBREVIATIONS}

ACF: Aceclofenac; FTIR: Fourier Transform Infrared spectroscopy; DSC: Differential Scanning Colorimetry; XRD: X-ray Diffraction; SEM: Scanning Electron Microscopy; NSAIDs: Non-steroidal anti-inflammatory drugs; COX-2: Cyclooxygenase-2; ERS PO: EudragitRS PO; PDI: Polydispersity index.

\section{REFERENCES}

1. Seyfoddin A, Shaw J, Al-Kassas R. Solid lipid nanoparticles for ocular drug delivery. Drug Deliv. 2010;17(7):467-89.

2. Peneva PT. Non-steroidal anti-inflammatory drugs for topical ophthalmic administration: Contemporary trends. Int J Pharm Sci. 2015;7(9):13-9.

3. Ahuja M, Dhake AS, Sharma SK, Majumdar DK. Topical Ocular Delivery of NSAIDs. AAPS J. 2008;10(2):229-41.

4. Raizman M. Corticosteroid Therapy of Eye Disease. Arch Ophthalmol. 1996;114(8):1000-1.

5. Katara R, Majumdar DK, Eudragit RL. 100-based nanoparticulate system of Aceclofenac for ocular delivery. Colloids Surf B Biointerfaces.2013;1:455-62.

6. Katara R, Sachdeva S, Majumdar DK. Design, characterization and evaluation of Aceclofenac loaded Eudragit RS 100 nanoparticulate System for ocular delivery. Pharmaceutical Development and Technology. 2018.

7. Katara R, Sachdeva S, Majumdar DK. Aceclofenac oil drops: characterization and evaluation against ocular inflammation. Pharm Dev Technol. 2017a;19:1-7.

8. Mehta P, Ahmed RH, Ahmad Z. Approaches in Topical Ocular Drug Delivery and Developments in the use of Contact Lenses as Drug-Delivery Devices. Ther Deliv. 2017;8(7):521-41.

9. Rodríguez VJ, Rodríguez, VL, Guzmán NM. Pharmaceutical technology can turn a traditional drug, dexamethasone into a first-line ocular medicine. A global perspective and future trends. Int J Pharm. 2017;516(1-2):342-51.

10. Katara R, Sachdeva S, Majumdar DK. Enhancement of ocular efficacy of Aceclofenac using biodegradable PLGA nanoparticles: Formulation and characterization. Drug Deliv TransI Res. 2017(b);7(5):632-41.

11. Sharma OP, Patel V, Mehta T. Nanocrystal for ocular drug delivery: Hope or hype. Drug Deliv and TransI Res. 2016;6(4):399-413.

12. Kamaleddin MA. Nano-ophthalmology: Applications and considerations. Nanomedicine. 2017;13(4):1459-72.

13. Yadav M, Dhole S, Chavan P. Nanosuspension: A novel techniques in drug delivery system. World Journal of Pharmacyand Pharmaceutical Sciences. 2014;3(12):410-33.

14. Hoobakht F, Ganji F, Vasheghani-Farahani E, Mousavi SM. Eudragit RS PO Nanoparticles for Sustained Release of Pyridostigmine Bromide. J Nanoparticle Res. 2013;15(9):1912-3.

15. Imperiale JC, Acosta GB, Sosnik A. Polymer-based carriers for ophthalmic drug delivery. J of Controlled Release. 2018;285:106-41.

16. Pawar P, Bhosale R, Bhandwalkar O, Duduskar A, Jadhav R. Water Soluble Chitosan Mediated Voriconazole Microemulsion as Sustained Carrier for Ophthalmic Application: In vitro/ex vivo/in vivo Evaluations. Open Pharmaceutical Sciences Journal. 2016;3(1):215-34.

17. Mudgil M, Pawar PK. Preparation and in vitro/ex vivo evaluation of moxifloxacin-loaded PLGA nanosuspension for ophthalmic application. Sci Pharm. 2013;81(2):591-606.

18. Dandagi P, Kerur S, Mastiholimath V, Gadad A, Kulkarni A. Polymeric ocular nanosuspension for controlled release of acyclovir: In vitro release and ocular distribution. IJPR. 2009;8(2):79-86.

19. Mali KK, Dias RJ, Ghorpade VS, Havaldar VD, Mohite VR. Formulation and Evaluation of Carbamazepine Liquisolid Compacts Using Novel Carriers. Indian Journal of Pharmaceutical Education and Research. 2017;51(2S):S69-78.

20. Dange SM. Formulation and Evaluation of Venlafaxine Nanostructured Lipid Carriers. Journal of Bionanoscience. 2014;8(2):81-9.

21. Nazeema TH, Sugannya PK. Synthesis and Characterisation of Silver Nanoparticle from Two Medicinal Plants and Its Anticancer Property. International Journal of Research in Engineering and Technology. 2014;2(1):49-56.

22. Costa P, Sousa L. Modeling and comparison of dissolution profiles. European Journal of Pharmaceutical Sciences. 2001;13(2):123-33.

23. Dave V, Paliwal S. A novel approach to formulation factor of Aceclofenac eye drops efficiency evaluation based on physicochemical characteristics of in vitro and in vivo permeation. Saudi Pharmaceutical Journal. 2014;22(3):2405. 
PICTORIAL ABSTRACT

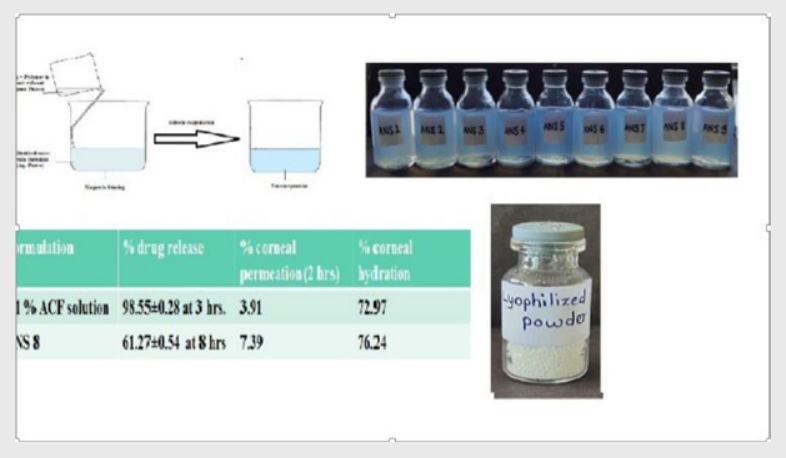

\section{SUMMARY}

Aceclofenac Nano suspensions were successfully prepared by using Eudragit RS PO polymer using Nano precipitation technique. Amongst the prepared formulations, ANS 8 formulation was selected as the optimized formulation based on particle size, zeta potential measurements, Polydispersity index, $\mathrm{pH}$ and drug entrapment efficiency. From ex vivo transcorneal study it was found that optimized formulation showed higher \% permeation of drug as compared with $0.1 \%$ Aceclofenac solution with no signs of corneal damage and eye friendly behavior. Hence it can be concluded that Aceclofenac Nano suspension prepared by using Eudragit RS PO polymer using Nano precipitation technique can be a choice for ocular inflammation.

About Authors

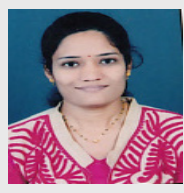

Miss. Sfurti S. Sakhare graduated (B. Pharm) 2006 from Government College of Pharmacy, Karad and M.Pharm in Pharmaceutics from Satara College of Pharmacy Satara, Shivaji University, Kolhapur (MS) India in 2008. Presently she is working as an Assistant Professor in Department of Pharmaceutics, Gourishankar Institute Pharmaceutical Education and Research Limb, Satara. She has published 21 Research articles in National - International peer reviewed journals and gave 10 presentations in National Conferences. Her area of interest is crystal engineering, evaluation of natural substances as pharmaceutical excipients, Bioadhesive drug delivery system.

Cite this article: Sakhare S, Shinde SD, Yadav AV, Shete AS. Studies on Formulation and Evaluation of Eudragit RS PO Based Nanoparticulate System of Aceclofenac for Ocular Delivery. Indian J of Pharmaceutical Education and Research. 2021;55(1s):s87-s99. 